\title{
Clarifying Definitions for the Massage Therapy Profession: the Results of the Best Practices Symposium ${ }^{\dagger}$
}

\author{
Ann B. Kennedy, LMT, BCTMB, DrPH, ${ }^{*}$ Jerrilyn A. Cambron, LMT, DC, MPH, PhD, ${ }^{2}$ \\ Patricia A. Sharpe, PhD, MPH, LMBT, ${ }^{3}$ Ravensara S. Travillian, PhD, NA-C, LMP, ${ }^{4}$ \\ Ruth P. Saunders, $\mathrm{PhD}^{5}$ \\ ${ }^{1}$ University of South Carolina School of Medicine Greenville, Human Performance Lab, Greenville, SC, USA, \\ ${ }^{2}$ Department of Research at the National University of Health Sciences, Lombard, IL, USA, ${ }^{3}$ University of South Carolina, \\ College of Social Work, Columbia, SC, USA, ${ }^{4}$ Pacific Northwest College of Allied Health Sciences, Seattle, WA, USA, \\ ${ }^{5}$ University of South Carolina Department of Health Promotion, Education, and Behavior, Columbia, SC, USA
}

Background: Massage therapists are at times unclear about the definition of massage therapy, which creates challenges for the profession. It is important to investigate the current definitions and to consider the field as a whole in order to move toward clarity on what constitutes the constructs within the profession.

Purpose: To determine how a sample of experts understand and describe the field of massage therapy as a step toward clarifying definitions for massage and massage therapy, and framing the process of massage therapy practice.

Setting: A two-day symposium held in 2010 with the purpose of gathering knowledge to inform and aid in the creation of massage therapy best practice guidelines for stress and low back pain.

Participants: Thirty-two experts in the field of massage therapy from the United States, Europe, and Canada.

Design: Qualitative analysis of secondary crosssectional data using a grounded theory approach.

Results: Three over-arching themes were identified: 1) What is massage?; 2) The multidimensional nature of massage therapy; and 3) The influencing factors on massage therapy practice.

Discussion: The data offered clarifying definitions for massage and massage therapy, as well as a framework for the context for massage therapy practice. These clarifications can serve as initial steps toward the ultimate goal of creating new theory for the field of massage therapy, which can then be applied in practice, education, research, and policy.

Conclusions: Foundational research into how experts in the profession understand and describe the field of massage therapy is limited. Understanding the potential differences between the terms massage and massage therapy could contribute to a transformation in the profession in the

\footnotetext{
${ }^{\dagger}$ Supplemental materials available at http://ijtmb.org
}

areas of education, practice, research, policy and/ or regulation. Additionally, framing the context for massage therapy practice invites future discussions to further clarify practice issues.

KEY WORDS: massage therapy; clinical practice; qualitative research; grounded theory; ecological framework; context

\section{INTRODUCTION}

Massage is generally defined as manipulation of soft tissue, whereas massage therapy is the systematic application of massage. ${ }^{(1,2)}$ Some sources extend the definition of massage therapy to include the systematic manual manipulation of soft tissue to enhance health and well-being. (3) The Massage Therapy Body of Knowledge (MTBOK) definition of massage therapy allows for health messages to be provided to clients/ patients for self-care and wellness purposes. ${ }^{(4)}$ However, these definitions may not sufficiently express what happens within massage therapy. For example, asking individuals if they have ever had a bad massage rarely leads to the answer of only poor manipulation of the tissue. Furthermore, Fortune and Gillespie ${ }^{(5)}$ observed that massage therapists are at times anxious about the nebulous nature of massage therapy including the inconsistent massage therapy definition and no true markers for therapist's excellence.

It is important to investigate the current definitions and to consider the field as a whole in order to move toward clarity on what constitutes the constructs within the profession. Durlak and DuPre ${ }^{(6)}$ have stated that obtaining an accurate picture of a phenomenon depends upon accurate measurement, and accurate measurement requires clear definitions. It is necessary to investigate how massage and/or massage therapy are defined and operationalized in practice in order to teach, practice, and research massage therapy accurately, effectively, and ethically. 


\section{Project Overview}

In 2005, the Massage Therapy Foundation (MTF) adopted a project to create standards of care, also known as best practices, for the massage therapy profession; in 2006, the MTF created a Best Practices Committee (BPC) to facilitate the project. In an effort to create a model for best practices, the BPC began its work by researching processes for creating these guidelines in other professions, looking at the available literature in massage therapy, and considering the clinical experience of practitioners and clients. The BPC concluded that the best method to gather information would be to hold a World Café-style symposium with experts in the field including educators, researchers, and practitioners. ${ }^{(7)}$ A paper was published in 2008 discussing the need for Best Practice Guidelines, potential topics for the proposed guidelines including massage therapy for low back pain, stress, and lymphedema management, as well as the proposed method for a suggested symposium. ${ }^{(8)}$ A two-day symposium was held in 2010 in conjunction with the MTF's Highlighting Massage Therapy in Complementary and Integrative Medicine Research conference in Seattle, Washington. The intended purpose of the symposium was to gather knowledge to inform and aid in the creation of massage therapy best practice guidelines for stress and low back pain. However, upon initial analysis, the $\mathrm{BPC}$ realized it did not have the information needed to create the intended model for best practices. Committee members knew the data were rich, intriguing, and valuable for the profession, but were unsure how to proceed with the analysis. In April of 2014, the MTF Board of Trustees and the BPC decided the best course of action would be to partner with an academic institution to help analyze the data and publish the results. This paper is a result of that partnership. Therefore, the purpose of this study is to examine the discussions from the symposium and determine how a sample of experts understand and describe the field of massage therapy as a step toward clarifying definitions for massage and massage therapy, and for framing massage therapy practice.

\section{METHODS}

\section{Qualitative Research Approach}

This qualitative study entailed secondary data analysis of cross-sectional data using a grounded theory approach. Grounded theory is often used to help develop theories and in the creation of conceptual models and frameworks from social research, and examples can be found from research in nursing, athletic training, and medicine, as well as other fields. (9-19) Applying a grounded theory methodology is inductive, in that the researcher begins with no set hypothesis and allows the theory to emerge from the data. ${ }^{(19,20)}$ The use of grounded theory in this case is essential, as this study aims to examine the opinions of experts in the field of massage therapy and use their perceptions to clarify constructs within the practice of massage therapy.

\section{Sampling}

Purposive sampling was used by the BPC when selecting participants for the symposium. The BPC invited participants with varying experience as clinicians, researchers, and educators. The BPC was concerned about a potential for the appearance of any real or perceived conflict of interest, so it excluded leaders from the professional massage organizations or providers of trademarked or registered styles of massage and/or bodywork.

The BPC created a list of 53 potential invitees and categorized them into researcher, clinician, and educator groups, with some participants being placed within multiple groups. An initial inquiry discussing the dates and location, along with a project outline, was sent to each of the 53 individuals asking for response of interest in participating and availability. Once the BPC received all the responses, it discussed the qualities and advantages of each potential individual and sent invitations to 36 people. Invited individuals were offered reimbursement for travel and hotel accommodation as an incentive to attend.

\section{World Café Model}

A World Café symposium follows seven principles: "set the context, create hospitable space, explore questions that matter, encourage everyone's contribution, connect diverse perspectives, listen together for patterns, and share collective discoveries." $(7,21)$ This model engages participants in dialogue, supports contributions from all participants, allows for diverse ideas and sharing communal thought processes, and helps to discover patterns. ${ }^{(7)}$ Participants assemble into small groups (4-6 individuals) at café-style tables for discussion; the discussions are used to engage participants in collaborative and appreciative inquiry to discover collective group knowledge and intelligence. ${ }^{(7,21)}$ Once discussion is completed, participants leave their small groups and create a new small group with different participants in order to build upon the previous discussions. Each small group has a "table host" who helps create a welcoming environment, encourages all people to participate, and shares insights from the previous discussions. ${ }^{(7,21)}$

\section{Setting Description}

In the meeting space, six round tables were set up with each table including space for a host/facilitator, six participants, butcher paper, crayons, and a recording device. The table host was not expected to 
moderate discussions, but actively participated with the other invited guests. The symposium was divided into four segments over two full days. The topics discussed in segments were as follows: offering context, massage and stress reduction, massage and low back pain, and managing the information. The questions for each topic are listed in Table 1. Each segment began with a presentation by a member of the BPC, which would establish guidelines for discussion, as well as pose questions around the topic to be discussed. Each segment was scheduled to last three hours broken up into 45-minute sessions, then a 10-minute break and five minutes to change tables. At the beginning of the next session, after participants changed tables, the table host would summarize the previous discussion and ask the new participants at the table to summarize what happened at their table; group dialogue then built upon the previous discussion.

\section{Data Collection}

A small audio recorder was placed in the center of each table to capture the small group discussions; at the beginning of the symposium, the participants gave consent for recording and transcription. Each round was electronically recorded and professionally transcribed for a total of 53 recorded sessions. The recordings lasted in length from 0 minutes (the recorder stopped working) to 178 minutes (recorded multiple rounds in a row) for a total of 2,679 minutes or 44.65 hours. The mean length of the recordings was 55 minutes and the median was 47 minutes.

TABle 1. Questions Posed to Symposium Participants in Each Round

\begin{tabular}{|c|c|}
\hline Topic & Questions \\
\hline \multirow[t]{5}{*}{ 1. Offering context } & If best practice guidelines are the answer, what is the question? \\
\hline & What do we not know, that if we did know, would make the most difference to this field? \\
\hline & What do we not have, that if we did have, could transform the future of Massage Therapy? \\
\hline & For what do you wish you had guidance? \\
\hline & For what do you wish others in your community of practice had guidance? \\
\hline \multirow[t]{12}{*}{ 2. Massage and stress relief } & From your experience and reading, what effects does massage therapy have on stress? \\
\hline & $\begin{array}{l}\text { What guidance would be helpful to a massage therapist who has a goal to help his/her clients reduce the } \\
\text { effect of stress on their health? }\end{array}$ \\
\hline & What is the role of massage therapy in stress management? \\
\hline & Reduce stressors? \\
\hline & Improve the client's ability to "cope" with stress? \\
\hline & Decrease the effects of stress on the body? - on the mind? \\
\hline & Others? \\
\hline & What role does context play in the clinical encounter where the goal is stress reduction? \\
\hline & What assumptions exist related to the effect of massage therapy on stress that should be challenged? \\
\hline & What are the red flags or contraindications in the context of massage therapy for stress management? \\
\hline & What do we still need to learn about the role of massage therapy in stress management? \\
\hline & What is the next level of thinking we need to address to reach our goal? \\
\hline \multirow[t]{8}{*}{ 3. Massage and low back pain } & What else do we know from experience? \\
\hline & What do we need as proof of usefulness? \\
\hline & What guidance would we like to have? \\
\hline & What guidance would we wish others to have? \\
\hline & What don't we know that would change massage practice for LBP? \\
\hline & What might we need to unlearn? \\
\hline & The question that is at the true core of all that we do... \\
\hline & Just who will be... \\
\hline \multirow[t]{3}{*}{ 4. Managing the information } & What knowledge do we have? \\
\hline & What is our knowledge based on? \\
\hline & How do we know what we know? \\
\hline
\end{tabular}




\section{Data Management}

All discussions from the symposium were collected electronically and uploaded to a cloud-based secure storage managed by the BPC. Transcripts were held in the same location. The BPC, the MTF staff liaison, as well as the first author (ABK), had access to the data.

\section{Data Analysis}

Data analysis was an iterative process; best practices for analyzing qualitative data were followed by first listening to each recording while reading and checking each transcript for accuracy by ABK. (22) While listening to the recordings and checking the transcripts, reflective memos were written and open coding began with ABK creating an initial qualitative codebook that would help guide analysis. Reflecting on these data helped to revise and reform the codebook and helped to guide analysis. (22) The initial codebook was taken back to the BPC for comment and revision. The BPC agreed with the proposed codes and offered some advice on potential grouping of themes; for example, listening, nurturing, and attention may be grouped under the theme of caring. Revisions were made based on feedback from the BPC and reflecting on the data. The codebook appears as supplementary material on the IJTMB website.

This codebook and all the transcripts were uploaded into QRS NVivo 10 $0^{(23)}$ for qualitative data management, coding, and analysis. A two-person team including $\mathrm{ABK}$ and RST coded the transcripts independently and met regularly to discuss and clarify emergent themes. Through the first cycle of coding, coders used provisional, descriptive, process, and simultaneous coding. Provisional coding addresses the fact that an initial codebook was created, in which the codes can be revised, modified, and/or deleted when necessary. ${ }^{(24)}$ Descriptive coding "assigns labels to data" and helps with grouping topics. (25) Process coding looks at the actions happening in the data. ${ }^{(24,25)}$ Simultaneous coding was utilized when more than one code was applied to a "chunk" of data showing the overlapping of concepts. ${ }^{(24,25)}$ After the initial coding pass by both coders, axial coding began investigating how the codes related to each other. ${ }^{(25)}$ Finally, theoretical coding occurred to help identify the central themes. ${ }^{(25)}$

\section{Member Check-ins}

To improve trustworthiness ${ }^{(25-27)}$ of the study, the results were presented to the symposium participants in five different scheduled Web conference formats. When planning the member checking sessions, (27-29) it was determined that a maximum of 10 participants would be permitted per conference to allow all members time to speak and discuss the results.

\section{Potential Research Bias}

With the criteria for reporting qualitative research $^{(30)}$ in mind, a reflection on the research team's participation with this project and the relationship to the data and the subject are important. Only one member of the research team, RST, was an original member of the BPC that presented the symposium and also helped with the coding and analysis. Of the authors, four are massage therapists who all have experience in clinical practice and/or research. Additionally, two of the team members, along with RST, are associated with the MTF through volunteering for the organization, and one had received a MTF research grant more than 10 years prior to this study. The other author brings research expertise but is not associated with the MTF or massage therapy. Specifically to help control for potential biases, two researchers analyzed the data, reflexive memoing was utilized, the results were shared with the participants in the member check-ins, and the final results were compared to the literature. ${ }^{(26-29)}$

\section{Ethical Considerations}

Ethical considerations in this project included Institutional Review Board (IRB) approval, the anonymity of the participants, and securing the documents in a password-protected, cloud-based storage system. The University of South Carolina IRB reviewed this project and the study was considered exempt.

\section{RESULTS}

\section{Participants}

Of the 36 individuals who received invitations, four declined and a total of 32 people participated in the symposium $(88.9 \%)$. A total of $59 \%$ of participants held multiple degrees/certifications; furthermore, $63 \%$ of the participants had more than one area of expertise as classified by the BPC. An informal poll was taken by the BPC during the symposium and it was estimated that the participants collectively held nearly 900 years of experience within the MT profession. Additional participant information can be found in Table 2.

\section{Themes}

Three over-arching themes were identified within the symposium discussions: 1) What is massage?; 2) The multidimensional nature of massage therapy; and 3) The influencing factors on massage therapy practice. Themes 2 and 3 had subthemes, and those subthemes will be discussed within each theme's section. 
Table 2. Demographics of Participants $(n=32)$

\begin{tabular}{|c|c|c|}
\hline & Variable & $n(\%)$ \\
\hline Female & & $23(72)$ \\
\hline \multicolumn{3}{|l|}{ Region } \\
\hline \multicolumn{3}{|c|}{ United States } \\
\hline & Northwest & $9(28)$ \\
\hline & West & $4(13)$ \\
\hline & Midwest & $3(9)$ \\
\hline & Northeast & $2(6)$ \\
\hline & Southeast & $1(3)$ \\
\hline \multicolumn{3}{|c|}{ Canada } \\
\hline & Central & $7(22)$ \\
\hline & West Coast & $3(9)$ \\
\hline & Prairies & $2(6)$ \\
\hline \multicolumn{3}{|c|}{ Europe } \\
\hline & England & $1(3)$ \\
\hline \multicolumn{3}{|l|}{ Degrees } \\
\hline & Bachelors (BA, BSc, BScN) & $7(13)$ \\
\hline & Masters (MEd, MPH, MS) & $6(11)$ \\
\hline & Doctoral (DC, DO, MD, ND, PhD) & $15(28)$ \\
\hline & $\begin{array}{l}\text { Licensed/Certified Massage Practitioner } \\
\text { (T, LMP, LMT, RMT) }\end{array}$ & $22(41)$ \\
\hline & $\begin{array}{l}\text { Additional Certifications (ATC, CKTP, } \\
\text { COHN, RN) }\end{array}$ & $4(7)$ \\
\hline \multicolumn{3}{|c|}{ Area of Expertise } \\
\hline & Best Practice Committee Member & $6(11)$ \\
\hline & Educator & $14(25)$ \\
\hline & Practitioner & $22(39)$ \\
\hline & Researcher & $15(26)$ \\
\hline
\end{tabular}

\section{Theme 1: What is massage?}

Many participants discussed the issue of a massage definition, with some trying to define it. Moreover, many of the participants indicated that massage was not simply touch or not simply soft-tissue manipulation.

The participants seemed to struggle with characterizing massage; as one participant stated, “... we don't even know what massage is." The difficulty of defining massage was stated by many other participants and this concept was found in almost half of the transcripts. Participants discussed which modalities would be considered massage and which would not (e.g., medical massage and energy work) and how the profession was hindered by multiple taxonomies. The multiple taxonomies, beliefs, and definitions about massage, according to the participants, were causing discord within the profession. One participant indicated that it seemed that the multiple taxonomies had led to people actually discussing the same concepts but with different words, and this led to confusion and discord. These differing taxonomies were likened to the parable of the blind people touching and subsequently trying to describe an elephant; touching in different places will lead to different descriptions of the same animal. ${ }^{(31)}$
Discussion about the lack of definition for massage led to exploration into what the participants felt was part of massage. Although the core of massage seems to be soft-tissue manipulation, the participants indicated that there is more to massage than simply soft-tissue manipulation, as illustrated in a discussion between three participants.

Participant 1: I do, I think that there is a distinction between them [massage and soft-tissue manipulation]; but it's not about what we do to the tissue. I think massage is creating change in the tissue. Relaxation massage, therapeutic massage, will create a change; you're applying a force. The distinction in my mind between massage and soft-tissue manipulation is the pattern, and the purpose, and the holistic nature of it. That's what makes a massage a massage, not just soft-tissue manipulation.

Participant 2: Well, and there's that question. [And] Massage is a part of body work, but is all body work massage? And that's right out of the Body of Knowledge. Massage is manipulation of soft tissue, but is all soft-tissue manipulation massage?

Participant 3: But it's a patterned and purposeful and therapeutic intended manipulation of soft [tissue], you know a holistic therapeutic intention with the soft-tissue manipulation. Whereas, softtissue manipulation can be cross-fiber friction at the lateral epicondyle...

Upon completion of the symposium, the consensus from the group was massage was more than soft-tissue manipulation; the intent, the pattern, and the purpose are of great significance.

\section{Theme 2: Multidimensional nature of massage therapy}

The systematic application of massage does not appear to cover the complete definition of massage therapy; massage therapy itself appears to have many dimensions/constructs which may not always be considered within the current definitions as was observed by the participants. Participants identified that the experience of receiving a massage may be part of the difference between simple manipulation of the soft tissue and true therapy. To illustrate this point, one participant stated: “...massage contains other elements of environment and psychosocial interaction beyond the mechanical or even neurological inputs of tissue, the input you're doing to the tissue."

The participants were curious about what the "ingredients" or elements were that would define and give structure to massage therapy. To categorize the specific dimensions, sub-themes were identified: role of health promotion/education messaging, influence 
of therapeutic relationships and communication, influence of therapist experience, education and skill, and influence of environment and context. The participants indicated these identified dimensions may have an impact on client outcomes.

\section{Subtheme: Role of health promotion/education messaging}

The experts felt that the non-hands-on component of discussing health messages and health promotion are an essential element to massage therapy especially in the role of self-care for clients. The symposium participants indicated these messages were an important part of massage therapy and these messages ranged from postural awareness, breath work, messages about mindfulness, stretches to help maintain loose muscles, discussions about exercise in general and specifically exercises to reduce pain, and potentially messages around nutrition to name a few. These messages were at times referred to in different manners from "client education" to "[client] self-care" to "homework" to "home care." The participants believed that massage therapy clients were more compliant with following self-care instructions given to them by massage therapists than by other health care providers. Additionally, the repeated following up about compliance with given messages at subsequent appointments could help to increase trust and improve therapeutic relationships.

\section{Subtheme: Influence of therapeutic relationships and communication}

The participants indicated that communication and therapeutic relationships are an important aspect of massage therapy; the experts also indicated that therapeutic relationships and communication might influence therapy outcomes. The participants felt that massage becomes therapy in the context of therapeutic relationships. Additionally, therapeutic relationships can be strengthened by positive communication.

The participants felt that students should be taught specific courses on communication to help improve skills and therapeutic relationships, as well as interprofessional communication. Furthermore, the participants felt that guidelines around communicating with clients should be created. Finally, the participants felt that one key element to successful massage therapy was communication. One participant stated: "... what's consistently there is that how you and I, as patient and therapist communicate, work together, listen to each other, and work with everything is... what is the profound nature of the therapy."

\section{Subtheme: Influence of therapist experience, education, and skill}

The next subtheme focuses on the therapist experience, education, and skill influencing the treatment, the plan of care, and potentially the outcomes. The participants also felt that the current level of education for entry level massage therapists is inadequate; and new therapists should seek out continuing education opportunities, find mentors, and work on many different people. The participants felt giving massage to different people over the course of a therapist's career will, in general, improve their skills and abilities and can therefore improve treatments and client outcomes. One example from the symposium can be seen in the discussion below:

Participant 1:... we talk about the five hundred hour therapist or the three thousand hour therapist. And really when they come out of school, they're all here. Right?

Participant 2: Until you've touched a thousand people. Yeah.

Participant 1: Yeah. And it's the practical experience that really gives you the true knowledge. Right? Whatever level of entry you have. And they need to understand that, is that they're entry level and just because you've done school doesn't mean you know enough.

\section{Subtheme: Therapeutic setting}

The participants noted that massage therapy outcomes are also influenced by the therapeutic setting in which they are performed. One participant said, "And, not to forget the element of the environment in which the massage is being given. The sound and the light and all those together bring about some effects, so it's not just the touching alone." Additionally, the experts discussed the concept of how treatment may be different depending on the setting in which it is given. As one participant stated, "I just have to say, from my own personal experience, that when I've had a massage in a resort or spa setting, that is obviously, sort of a prescribed protocol that really doesn't take into effect who the person is on the table." The participants indicated that the setting and environment should be considered when discussing the goals of therapy with clients. They were concerned that some settings may have less educated therapists not equipped to deal with helping clients with multiple morbidities and those clients should be seen in a more therapeutic setting.

\section{Theme 3: Influencing factors on massage therapy practice}

This theme looks at contextual factors that may have an impact on how massage therapy is practiced. This theme yielded subthemes including: safety, holistic practice, isolation of practice, and service or health industry?

\section{Subtheme: Safety}

The concept of safety was of great importance for the participants. This concept was not looking at 
the potential adverse events that may occur in massage therapy practice. This was the idea that clients needed to feel safe, emotional and/or psychologically, to effectively be able to receive treatment. The significance that these experts place on safety and the potential influence on outcomes from treatment can be seen in the following discussion between two participants.

Participant 1: So, what I hear you saying is, maybe that element of massage therapy, that safety component...I think it's something we talk about in a roundabout sort of ways; but you're suggesting that clinically, that's a critical element that massage therapy?

Participant 2: From my perspective, it's at the core. Whatever else we might do, if we're not facilitating a client to feel safe, if they remain guarded, if they remain slightly anxious. then...

Participant 1: [interjecting] Outcomes are gonna be limited.

The participants stated that clients must feel safe in order for the parasympathetic nervous system function to increase and allow the client to truly relax. This environment of safety is strengthened by the boundaries and ethics of the therapist. Much like trust, the clients' feelings of safety may increase over time with experience with massage therapy and with the therapist.

\section{Subtheme: Holistic practice}

The experts indicated that massage therapy practice is holistic care, which supports wellness and addresses the whole person. Moreover, participants spoke about treating clients within their social structure, potentially including their relationships within their family structure and their community. When working with clients, the participants stated, it is important to see the whole picture of the client's life: How do they sleep? What do they do during the day? Do they have satisfying relationships? These areas can influence the reasons why a client seeks therapy, as well as may provide insights into the needed therapy itself. By listening to a client's story, information can be gathered to treat the whole person. As one participant said:

One of the things that is unique about the massage therapy profession is that we don't always go for fixing a single issue. You know, that we're very multidimensional in our approach to things. We're using a lot of different techniques, a lot of different ideas, and we're approaching it from an exchange of ideas, comments, energies. I listen to your whole story. I don't just treat your knee-I treat your whole body.

\section{Subtheme: Isolation of practice}

The participants expressed that one aspect that seems to shape the profession is massage therapists are often practicing alone. Therapists, in general, practice without other professionals to check in with about client issues. As one participant reported: "I think a lot of practitioners tend to feel very isolated, because a lot of them work in private practice. It's not...it's more common than it used to be, but it's still not the norm, for say hospitals to have massage therapists as part of the health care team." This isolation can have a profound impact on therapists; social isolation and loneliness, which can not only affect the massage therapy business and treatment of clients, but also a therapist's emotional state.

\section{Subtheme: Service or health industry?}

Participants discussed in which industry massage therapy practice belonged. There was not agreement on this issue; some felt that massage was part of the service industry and one participant said, "I think that it's a service industry. As a service industry, yeah, not everyone considers us to be [in the] health care field." Others felt massage therapy was part of health promotion and health care:

We're in the field of health and health care and delivery system and disease model. And we also toggle between that other space where sometimes we're put in that spa setting, or we're put in that-I just wanna feel good setting. But, if we're gonna keep ourselves, our profession, in the context of actually being health care providers, that is health promotion. And that's a field within Public Health. It's an area; it's still in development. And it's, in my mind, you have health promotion as kind of the overhead, and then you have prevention, and then you have these other little chronic conditions, and all of these other places where we actually fit. So if we look at ourselves as health promoters, then we fit into that realm of health care provider as health promoters.

Some felt that the line between service (spa) and health care was blurry. This unclear distinction was illustrated by client's expecting service/relaxation outcomes in therapeutic settings and other times therapeutic outcomes (e.g., pain management) from service/spa type settings. This lack of clarity causes tension, for not only the practice of massage therapy but also for the public.

Finally, it was clear that this non-agreement on where the profession is situated in industry could have an impact on how massage therapy may be practiced; this led to further discussions around the concept of tiered credentialing/licensing for therapists. The participants discussed the possible need to tier massage credentials to help with public safety; however, not 
all participants agreed with the concept of moving toward tiered credentialing.

\section{Member Check-Ins}

To help improve the validity of the results, five Web conferences were conducted to see if the participants agreed with the findings drawn from the symposium. A total of nine of the original 32 participants joined in the member check-ins.

All the participants who did participate in the Web conferences agreed with the conclusions drawn by the research team. When specific feedback given, it was generally related to the conceptual models in the types and directions of lines; this was more evident for the models presented in the second manuscript focusing on a framework for massage therapy. ${ }^{(32)}$ Feedback was incorporated into the models where needed. Additionally, one participant stated that they hoped that these results would help to "create a bridge between practice and research."

\section{DISCUSSION}

While the symposium was intended to help create best practice guidelines around stress and low back pain, discussion was more general in nature about massage therapy practice rather than specific protocols to treat specific conditions. As identified by the participants from the symposium, clarification of the definitions for massage and massage therapy, as well as framing the context for massage therapy practice, are needed.

The final phase in grounded theory methodology for qualitative research is to compare the emergent themes to concepts in the literature. ${ }^{(33)}$ Therefore, this paper aspires to contribute clarity to the field with definitions and framing the context for massage practice. These are the first steps toward the ultimate goal, creating new theory for the field of massage therapy, which can then be applied in practice, education, research, and policy.

\section{Massage}

A large part of the lack of clarity in definition may be due to the common practice of using the terms "massage" and "massage therapy" interchangeably when, in fact, they appear to be two separate concepts. Symposium participants felt that massage is more than soft-tissue manipulation as it is usually defined in the literature. ${ }^{(1,2)}$ As stated previously, MTBOK does give a more complete definition, ${ }^{(4)}$ however, the "patterned and purposeful" aspects of massage identified by the participants seem to be missing.

Therefore, for defining the construct massage, we have modified a portion of the $\mathrm{MTBOK}^{(4)}$ definition and incorporated the concept that massage is more than soft-tissue manipulation from the symposium participants, with the following definition:

Massage is a patterned and purposeful soft-tissue manipulation accomplished by use of digits, hands, forearms, elbows, knees and/or feet, with or without the use of emollients, liniments, heat and cold, hand-held tools or other external apparatus, for the intent of therapeutic change.

\section{Massage Therapy}

As the participants discussed, massage therapy seems to be more than simply the application of massage. Participants noted health messaging occurring within sessions is often ignored as part of massage therapy. The literature does indicate there is a non-hands-on portion. This can be seen within the MTBOK $^{(4)}$ definition, as well as the Boulanger and Campo study ${ }^{(34)}$ which documented massage therapists performing health promotion activities within practice such as increasing water intake, stretching for self-care, and stress management activities.

As the participants stated, therapeutic relationships are an understudied area within the profession. Research suggests that the relationship between client and therapist is of particular importance, as this relationship may allow for more depth and intensive treatment, more positive outcomes of treatment, and may be similar to the therapeutic relationships in psychotherapy. ${ }^{(35)}$ More research is needed to investigate the importance of the therapeutic relationship within massage therapy. Additionally, communication in and of itself has been seen as a way to improve the therapeutic relationship in other professions, but has not been examined within massage therapy. ${ }^{(36-38)}$

It also seems as though therapists' education and experience may have an impact on the way therapy is implemented as well as outcomes, as the participants discussed. ${ }^{(39,40)}$ It has been mentioned in the literature that the therapeutic setting in which massage therapy is delivered may have an influence on outcomes, but that has yet to be studied. ${ }^{(41)}$ Participant discussion was consistent with reports from the literature. Therefore, the massage therapy construct is defined as:

Massage therapy consists of the application of massage and non-hands-on components, including health promotion and education messages, for self-care and health maintenance; therapy, as well as outcomes, can be influenced by: therapeutic relationships and communication; the therapist's education, skill level, and experience; and the therapeutic setting.

An illustration of the massage therapy definition can be seen in Figure 1. Each of these levels builds upon each other and may influence the levels within it as well as outcomes. 


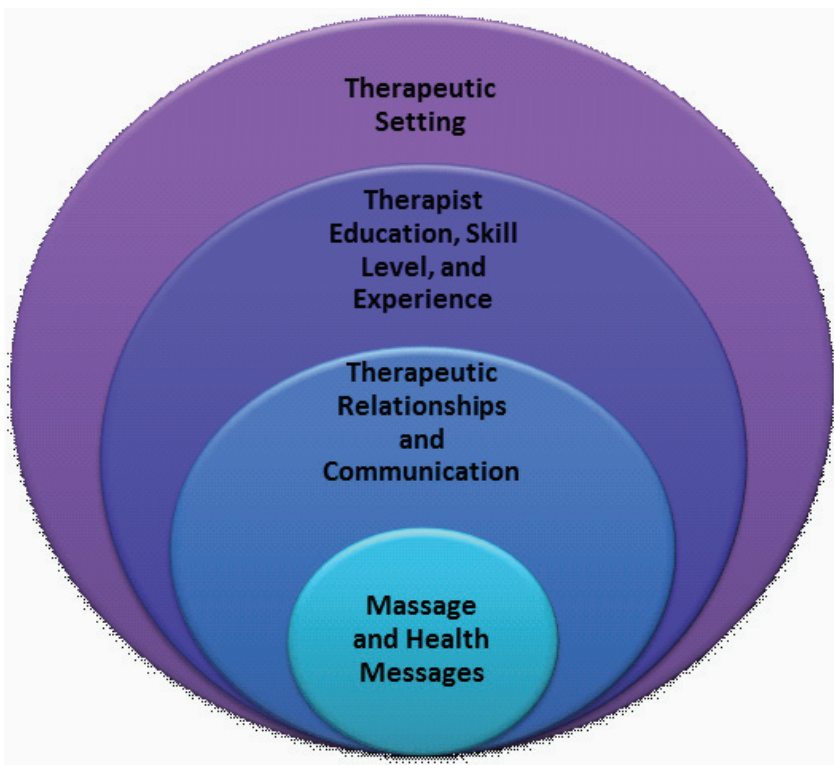

FIGURE 1. Conceptualization of massage therapy definition. The hands-on portion, as well as the non-hands-on portion, is seen in the center; therapy and client outcomes, may be influenced by the encircling layers including therapeutic relationships and communication, the therapist's education, skill level and experience, as well as the therapeutic setting.

\section{Framing Massage Therapy and Massage Therapy Practice}

With the constructs of massage and massage therapy clarified, it is important to examine massage therapy practice. Examining massage therapy practice as a process is beyond the scope of this manuscript and is addressed in a separate manuscript. ${ }^{(32)}$ However, the participants indicated important contextual factors that may impact the way massage therapy is practiced, which are addressed here. The Bronfenbrenner ecological framework assists in understanding the multiple layers of contextual factors, which appear impact massage therapy practice. ${ }^{(42)}$ Bronfenbrenner's framework considers levels of contextual influence on human development; micro-, meso-, exo-, and macrosystem levels. ${ }^{(42)}$ In this context, applying the results of the symposium to the model, micro-, meso-, and macro-levels have been identified. The micro-level includes those practice elements that are client-focused. Meso-levels are therapist focused; this is the portion of practice that directly impacts the individual therapist on a personal level. Finally, the macro-level are system focused. ${ }^{(43-45)}$ The framing elements identified by the participants are micro-level safety and holistic practice, meso-level isolation, and macro-level the division in the profession (Figure 2).

Two concepts are specified on the micro-level of contextual elements that frame massage therapy, safety and holistic nature of practice. The participants indicated that creating a safe environment is essential. It is important for the massage therapist to create a feeling of safety within an environment where clients may feel very vulnerable, especially when unclothed and touched by a stranger. Learning to put patients at ease may be essential for positive therapy outcomes; however, no research to date has looked at the concept of the client feeling safe in the environment to receive massage therapy. However, the concept of psychological and/or emotional safety has been explored in other health care literature, in particular nursing practice literature. Within these studies, "feeling safe" is identified as a sense of security and a freedom from harm, be this physical or psychological harm, that is established by a sense of trust and being cared for by a clinician. ${ }^{(46-50)}$ It appears from this literature that establishing therapeutic relationships may help to increase client/patients' feelings of safety.

The participants noted that massage therapists worked in a holistic manner and addressed the "whole person" during care, and this included working within the client's social context. The wellness model looks at health from a holistic perspective in which the mind and body are seen as interconnected. ${ }^{(51)}$ Studies have noted that massage therapists tend to practice holistically by attending to both internal and external factors when treating a client. ${ }^{(35,52)}$

The middle influence, or meso-level, focuses on the context for the therapist. The participants discussed the solo nature of massage therapy practice and how therapists may feel isolated. Research also indicates that massage therapy practice can also be isolating. ${ }^{(5)}$ Fortune and Gillespie ${ }^{(5)}$ postulate that even for those therapists in group practices, isolation can be a factor that can increase anxiety for therapists. Too much isolation may influence how massage therapists practice and may be one reason for the high attrition of therapists in the field. ${ }^{(53,54)}$ Isolation could be studied in the future to investigate the impact on therapists and practice.

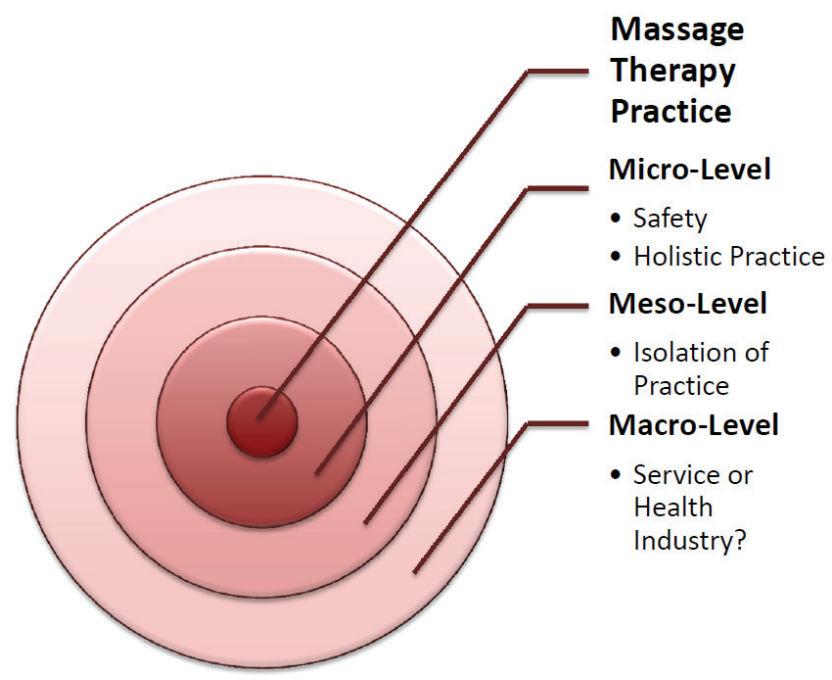

FIGURE 2. Framing massage therapy practice. Micro- (Safety and Holistic Practice), meso-(Isolation of Practice), and macro- (Service or Health Industry?) levels are identified. 
Finally, at the macro-level, participants noted a lack of consensus to which industry massage therapy belongs; they were not clear whether massage therapy belongs in a service or health industry or in both industries simultaneously. While no United States literature discusses this divide in the profession, a group of researchers identify the "identity crisis" for the profession in Canada, which seems to mirror the problems in the US. ${ }^{(55)}$ The Canadian researchers point out that to improve business for massage therapists, it should be connected to aesthetic and cosmetological services, while others point to the medical community, and still others want massage therapy in the wellness/ prevention role. ${ }^{(55)}$ These identity crises are a barrier to the advancement of the profession in Canada and similar crises appear to be occurring in the US.

\section{Limitations}

This study does have limitations. In particular, the data were originally gathered to create best practice guidelines for massage therapy on stress and low back pain; however, the data did not support the creation of guidelines and were then analyzed to find relevant information for the profession. The limitation, therefore, is in the concept that the results are different from the intended purpose of the data collection. Additionally, the participants themselves were very experienced and they may have had biases, which may have skewed the discussion. Also, the de-identified data did not allow for filtering of responses by the participants' area of expertise. Furthermore, all but one of the participants came from North America, which may limit some of the findings; practitioners from areas other than North America should interpret the findings with caution. These proposed definitions may also not comply with some scopes of practice; therefore, massage therapists should consider them with a respect to their current regulation. While these results were presented to participants through the member check-ins, only $28 \%$ chose to participate in the process and those who did not participate may not have agreed with the conclusions drawn from the data. Finally, while qualitative studies guided by grounded theory can help to understand complex concepts by helping to inform the creation of conceptual models, those models need to be tested to verify their viability and reliability. ${ }^{(19,33,56)}$

\section{CONCLUSION}

Research into how experts in the profession understand and describe the field of massage therapy is limited. The analysis indicated a need for clarifying the definitions of massage and massage therapy, as well as describing the context of massage therapy practice. As the experts themselves stated, massage therapy is complex and has many components that are not always recognized. Understanding the potential differences in the terms massage and massage therapy could potentially transform the profession from the areas of education, practice, research, policy, and/or regulation. Changes at the organizational/systems level will be needed to consider including these definitions within the profession. It is recommended that the professional and regulatory organizations work together to pursue the next steps including: implementing these definitions within their organizations, investigate changing scopes of practices, funding research which incorporates all dimensions of massage therapy, and helping to advocate for further education for therapists. Acknowledging factors that may impact practice invites the opportunity for discussions on multiple points such as: How can massage therapists help their clients feel safe? How does the profession help to limit the isolation of the individual practitioner? What sort of messaging can the profession include to the public about the holistic nature of practice? Finally, in what industry does the profession truly belong?

While the goal of the BPC was to create conditionspecific best practice documents, the participants felt that a more basic document was needed. This work may be the start of that foundation on which future best practices can be built.

\section{ACKNOWLEDGMENTS}

We would like to thank and acknowledge the Massage Therapy Foundation for funding this project from the initial symposium, support for the Best Practices Committee, and final funding for additional research support. We would also like to thank the Best Practices Committee for their diligence in the pursuit of bringing the results forward. The participants of the symposium are also thanked for the desire to help move the profession forward. Additionally, a special thank you needs to be given to John Balletto, LMT, past chair of the BPC, his dedication to the profession and to the project as well as availability to answer questions is truly appreciated.

\section{CONFLICT OF INTEREST NOTIFICATION}

R. P. Saunders declares no competing interests. A. B. Kennedy and J. A. Cambron both sit on the Board of Trustees for the Massage Therapy Foundation (MTF). R. S. Travillian was a volunteer for the MTF until 2015 and was part of the Best Practices Committee that produced the symposium that generated the data. P. A. Sharpe received a 2000-2001 grant from the MTF.

\section{COPYRIGHT}

Published under the CreativeCommons AttributionNonCommercial-NoDerivs 3.0 License. 


\section{REFERENCES}

1. Tappan FM. Tappan's Handbook of Healing Massage Techniques: Classic, Holistic, and Emerging Methods, 4th ed. Upper Saddle River, N.J: Pearson/Prentice Hall; 2004.

2. Dryden T, Moyer CA, editors. Massage Therapy: Integrating Research and Practice. Champaign, IL: Human Kinetics; 2012.

3. Moyer CA, Rounds J, Hannum JW. A meta-analysis of massage therapy research. Psychol Bull. 2004;130(1):3-18.

4. Fong B, Lavery M, Pierce K, Salvo S, Schenkman S, Schmidt D, et al. Massage Therapy Body of Knowledge [Internet]. American Massage Therapy Association, Associated Bodywork and Massage Professionals, Federation of State Massage Therapy Boards, Massage Therapy Foundation, National Certification Board for Therapeutic Massage and Bodywork; 2010. Available from: www.MTBOK.org

5. Fortune LD, Gillespie E. The influence of practice standards on massage therapists' work experience: a phenomenological pilot study. Int J Ther Massage Bodyw. 2010;3(3):5-11.

6. Durlak JA, DuPre EP. Implementation matters: a review of research on the influence of implementation on program outcomes and the factors affecting implementation. Am J Community Psychol. 2008;41(3-4):327-350.

7. Brown J, Isaacs D. The World Café: Shaping Our Futures Through Conversations That Matter, 1st ed. San Francisco, CA: Berrett-Koehler Publishers; 2005.

8. Grant KE, Balletto J, Gowan-Moody D, Healey D, Kincaid $\mathrm{D}$, Lowe $\mathrm{W}$, et al. Steps toward massage therapy guidelines: a first report to the profession. Int $J$ Ther Massage Bodyw. 2008;1(1):19-36.

9. Cochran A, Elder WB. A model of disruptive surgeon behavior in the perioperative environment. J Am Coll Surg. 2014;219(3):390-398.

10. Green HE. Use of theoretical and conceptual frameworks in qualitative research. Nurse Res. 2014;21(6):34-38.

11. Mylopoulos M, Lohfeld L, Norman GR, Dhaliwal G, Eva KW. Renowned physicians' perceptions of expert diagnostic practice. Acad Med. 2012;87(10):1413-1417.

12. Pitney WA, Ehlers GG. A grounded theory study of the mentoring process involved with undergraduate athletic training students. J Athl Train. 2004;39(4):344-351.

13. Sbaraini A, Carter SM, Evans RW, Blinkhorn A. How to do a grounded theory study: a worked example of a study of dental practices. BMC Med Res Methodol. 2011;11:128.

14. Matthew-Maich N, Ploeg J, Dobbins M, Jack S. Supporting the uptake of nursing guidelines: what you really need to know to move nursing guidelines into practice. Worldviews Evid-Based Nurs. 2013;10(2):104-115.

15. Ploeg J, Markle-Reid M, Davies B, Higuchi K, Gifford W, Bajnok I, et al. Spreading and sustaining best practices for home care of older adults: a grounded theory study. Implement Sci. 2014;9:162.

16. Solà I, Carrasco JM, Díaz Del Campo P, Gracia J, Orrego C, Martínez F, et al. Attitudes and perceptions about clinical guidelines: a qualitative study with Spanish physicians. PloS One. 2014;9(2):e86065.

17. Veldhuijzen W, Ram PM, van der Weijden T, van der Vleuten CPM. Communication guidelines as a learning tool: an exploration of user preferences in general practice. Patient Educ Couns. 2013;90(2):213-219.

18. SinuffT, Kahnamoui K, Cook DJ, Giacomini M. Practice guidelines as multipurpose tools: a qualitative study of noninvasive ventilation. Crit Care Med. 2007;35(3):776-782.

19. Glaser BG, Strauss AL. The Discovery of Grounded Theory: Strategies for Qualitative Research [Internet]. Chicago: Aldine Pub.; 1973. Accessed February 26, 2015. Available from: http:// search.ebscohost.com/login.aspx?direct=true $\&$ scope $=$ site $\& \mathrm{db}$ $=$ nlebk \&db=nlabk\&AN=580315

20. Licqurish S, Seibold C. Applying a contemporary grounded theory methodology. Nurse Res. 2011;18(4):11-16.

21. The World Cafe Community Foundation. Cafe-To-Go-Revised [Internet]. 2015. Accessed March 14, 2016. Available from: http://www.theworldcafe.com/wp-content/uploads/2015/07/ Cafe-To-Go-Revised.pdf

22. Maxwell JA. Qualitative Research Design: an Interactive Approach, 3rd ed. Thousand Oaks, CA: SAGE Publications; 2013.

23. QSR International Pty Ltd. NVivo qualitative data analysis software [Internet]. Melbourne, Australia: QSR International Pty Ltd.; 2012. Available from: https://www.qsrinternational. com/default.aspx

24. Miles MB, Huberman AM. Qualitative Data Analysis: an Expanded Sourcebook, 2nd ed. Thousand Oaks, CA: Sage Publications; 1994.

25. Saldaña J. The Coding Manual for Qualitative Researchers, 2nd ed. Los Angeles: SAGE; 2013.

26. Patton MQ. Qualitative Research and Evaluation Methods, 3 ed. Thousand Oaks, CA: Sage Publications; 2002.

27. Krefting L. Rigor in qualitative research: the assessment of trustworthiness. Am J Occup Ther. 1991;45(3):214-222.

28. Morrow SL. Quality and trustworthiness in qualitative research in counseling psychology. J Couns Psychol. 2005;52(2):250-260.

29. Shenton AK. Strategies for ensuring trustworthiness in qualitative research projects. Educ Inf. 2004;22(2):63-75.

30. Tong A, Sainsbury P, Craig J. Consolidated criteria for reporting qualitative research (COREQ): a 32-item checklist for interviews and focus groups. Int J Qual Health Care. 2007;19(6):349-357.

31. Blubaugh B. The Blind Men and The Elephant [Internet]. Washington: Peace Corps. Accessed March 16, 2016. Available from: http://www.peacecorps.gov/wws/stories/blindmen-and-elephant/

32. Kennedy AB, Cambron J, Sharpe P, Travillian RS, Saunders RP. Process for massage therapy practice and essential assessment. J Bodyw Mov Ther. 2016;1.

33. Pandit NR. The creation of theory: a recent application of the grounded theory method. Qual Rep. 1996;2(4):1-15.

34. Boulanger K, Campo S. Are personal characteristics of massage therapists associated with their clinical, educational, and interpersonal behaviors? Int $J$ Ther Massage Bodyw. 2013;6(3):25-34.

35. Smith JM, Sullivan SJ, Baxter GD. The culture of massage therapy: valued elements and the role of comfort, contact, connection and caring. Complement Ther Med. 2009;17(4):181-189.

36. Di Blasi Z, Harkness E, Ernst E, Georgiou A, Kleijnen J. Influence of context effects on health outcomes: a systematic review. Lancet. 2001;357(9258):757-762. 
37. McAllister M, Matarasso B, Dixon B, Shepperd C. Conversation starters: re-examining and reconstructing first encounters within the therapeutic relationship. $J$ Psychiatr Ment Health Nurs. 2004;11(5):575-582.

38. Mackereth PA, Booth K, Hillier VF, Caress A-L. What do people talk about during reflexology? Analysis of worries and concerns expressed during sessions for patients with multiple sclerosis. Complement Ther Clin Pract. 2009;15(2):85-90.

39. Donoyama N, Shibasaki M. Differences in practitioners' proficiency affect the effectiveness of massage therapy on physical and psychological states. J Bodyw Mov Ther. 2010;14(3):239-244.

40. Moraska A. Therapist education impacts the massage effect on postrace muscle recovery. Med Sci Sports Exerc. 2007;39(1):34-37.

41. Brett J, Brimhall J, Healey D, Pfeifer J, Prenguber M. Competencies for public health and interprofessional education in accreditation standards of complementary and alternative medicine disciplines. Explore. 2013;9(5):314-320.

42. Bronfenbrenner U. Toward an experimental ecology of human development. Am Psychol. 1977;32(7):513-531.

43. Liu X, Dou L, Zhang H, Sun Y, Yuan B. Analysis of context factors in compulsory and incentive strategies for improving attraction and retention of health workers in rural and remote areas: a systematic review. [Internet]. Hum Resour Health. 2015;13(1). Accessed August 4, 2015. Available from: http://www.human-resources-health.com/content/13/1/61

44. Hong JS, Lee C-H, Lee J, Lee NY, Garbarino J. A review of bullying prevention and intervention in south korean schools: an application of the social-ecological framework. Child Psychiatry Hum Dev. 2014;45(4):433-442.

45. Chilenski SM. From the macro to the micro: a geographic examination of the community context and early adolescent problem behaviors. Am J Community Psychol. 2011;48(3-4): 352-364.

46. Smith CP, Freyd JJ. Dangerous safe havens: institutional betrayal exacerbates sexual trauma. J Trauma Stress. 2013;26(1):119-124.
47. Mollon D. Feeling safe during an inpatient hospitalization: a concept analysis. J Adv Nurs. 2014;70(8):1727-1737.

48. Taua C, Neville C, Scott T. Mental health inpatient experiences of adults with intellectual disability. Int J Ment Health Nurs. 2015;24(6):507-518.

49. Lovink MH, Kars MC, de Man-van Ginkel JM, Schoonhoven L. Patients' experiences of safety during haemodialysis treatment — a qualitative study. J Adv Nurs. 2015;71(10):2374-2383.

50. Wassenaar A, van den Boogaard M, van der Hooft T, Pickkers P, Schoonhoven L. "Providing good and comfortable care by building a bond of trust": nurses views regarding their role in patients' perception of safety in the Intensive Care Unit. J Clin Nurs. 2015;24(21-22):3233-3244.

51. Larson JS. The conceptualization of health. Med Care Res Rev. 1999;56(2):123-136.

52. Fortune LD, Hymel GM. Creating integrative work: a qualitative study of how massage therapists work with existing clients. J Bodyw Mov Ther. 2015;19(1):25-34.

53. American Massage Therapy Association. Massage Profession Research Report 2014 [Internet]. Evanston, IL: American Massage Therapy Association; 2014. Available from: https://www. amtamassage.org/uploads/cms/documents/2014_mprr_professional_version_web_memberonly.pdf

54. American Bodywork and Massage Professionals. Massage Profession Metrics [Internet]. Accessed November 14, 2014. Available from: http://www.massagetherapy.com/media/metrics_income_employment.php

55. Shroff FM, Sahota IS. The perspectives of educators, regulators and funders of massage therapy on the state of the profession in British Columbia, Canada. Chiropr Man Ther. 2013;21(1):2.

56. Charmaz K. Constructing Grounded Theory: a Practical Guide Through Qualitative Analysis, 1st ed. Thousand Oaks, CA: Sage Publications; 2006.

Corresponding author: Ann Blair Kennedy, University of South Carolina School of Medicine Greenville, 701 Grove Road, Greenville, SC 29605, USA E-mail:kenneda5@greenvillemed.sc.edu 